\title{
Influence on persistence and adherence with oral bisphosphonates on fracture rates in osteoporosis
}

\author{
Ariane Höer' \\ Cornelia Seidlitz' \\ Holger Gothe' \\ Guido Schiffhorst' \\ Melvin Olson ${ }^{2}$ \\ Peyman Hadji ${ }^{3}$ \\ Bertram Häussler ${ }^{\prime}$ \\ 'IGES Institut, Friedrichstrasse \\ 180, D-10II 7 Berlin, Germany; \\ ${ }^{2}$ Novartis Pharma AG; ${ }^{3}$ Department \\ of Gynaecology, University hospital \\ of Giessen and Marburg GmbH, \\ Marburg, Germany
}

\begin{abstract}
Background and Aim: Oral bisphosphonates have been shown to reduce the risk of fractures in patients with osteoporosis. It can be assumed that the clinical effectiveness of oral bisphosphonates depends on persistence with therapy.

Methods: The influence of persistence with and adherence to oral bisphosphonates on fracture risk in a real-life setting was investigated. Data from 4451 patients with a defined index prescription of bisphosphonates were included. Fracture rates within 180, 360, and 720 days after index prescription were compared between persistent and non-persistent patients. In an extended Cox regression model applying multiple event analysis, the influence of adherence was analyzed. Persistence was defined as the duration of continuous therapy; adherence was measured in terms of the medication possession ratio (MPR).

Results: In patients with a fracture before index prescription, fracture rates were reduced by $29 \%$ ( $p=0.025$ ) comparing persistent and non-persistent patients within 180 days after the index prescription and by $45 \%(\mathrm{p}<0.001)$ within 360 days. The extended Cox regression model showed that good adherence (MPR $\geq 0.8$ ) reduced fracture risk by about $39 \%$ (HR 0.61 , 95\% CI 0.47-0.78; $\mathrm{p}<0.01)$.
\end{abstract}

Conclusions: In patients with osteoporosis-related fractures, good persistence and adherence to oral bisphosphonates reduced fracture risk significantly.

Keywords: compliance, fracture risk, oral bisphosphonates, persistence

\section{Introduction}

Osteoporosis is characterized by a low bone density and deterioration of bone tissue, associated with an increased risk of fractures. International guidelines on treatment and prevention of osteoporosis recommend the use of bisphosphonates such as alendronate and risedronate. ${ }^{1}$ Currently, compounds are available as an oral daily regimen or as single tablet taken once a week. Recently, preparations have become available which can be given either orally once a month or administered parenterally every 3 months or yearly. In clinical trials, oral bisphosphonates have been shown to reduce the risk of fractures in patients with osteoporosis. ${ }^{2}$

In clinical practice, however, a low persistence probably limits this effect. Observational studies demonstrate that good compliance is associated with a reduced risk of fracture. ${ }^{3-5}$ Osteoporosis, as a chronic condition, necessitates regular use of medication, but the precautions detailed in the dosing instructions of oral bisphosphonates (ie, remaining upright for $30 \mathrm{~min}$ ) may reduce adherence. Thus, persistence and adherence are crucial elements in determining the success of any long-term therapy for osteoporosis.

The focus of this study was on the influence of persistence with and adherence to bisphosphonates on fracture risk in patients with osteoporosis in a naturalistic setting. 
Therefore, we compared fracture rates in patients with osteoporosis according to persistence and adherence within 180,360 , and 720 days after index prescription.

\section{Material and methods}

\section{Data and time frame}

In order to build a cohort for a retrospective cohort study, we extracted data from a claims database of a German statutory sickness fund, covering about 1.4 million lives. Data recorded from 2000 to 2004 were considered.

The database covers information on demographic variables (age and gender), enrollment period, hospitalization including diagnoses (ICD-10 code), admission and discharge date, sick leave including diagnoses (ICD-10 code) and related number of days absent from work, and outpatient prescription data. The prescription data contains the national drug code (PZN: Pharmazentralnummer) and date of filled prescriptions. The PZN code provides information on active substance, package size (ie, number of pills), and dosage strength. The anonymity of the insurance data was protected by the use of pseudonyms.

\section{Identification of the study cohort}

We identified patients enrolled in the health plan between 2000 and 2004 for at least 90 days and aged $\geq 45$ years. Inclusion was restricted to patients with at least one prescription of an oral bisphosphonate (according to PZN code) indicated for treatment of osteoporosis in Germany (alendronate, risedronate, etidronate). Patients with a recorded diagnosis of cancer, AIDS or Paget's disease were excluded. An index prescription was defined as the first prescription of alendronate or risedronate (first prescriptions of etidronate were not considered because of the low percentage of this compound in the market) with an observation time of at least 360 days before and 180 days after the index prescription, and which met the criteria of no prescription of any bisphosphonate within 180 days before the corresponding index date. Thus we included patients with as well as without previous fractures.

\section{Statistical analysis}

Primary end points of the study were incident fractures. Fracture rates of patient with or without a previous fracture (before index prescription) within 180,360, and 720 days after the index prescription were compared between persistent and non-persistent patients. Patients were classified as "persistent" if the therapy duration was at least as long as the time period considered. In an extended Cox regression model, time to osteoporosis-related fractures was analyzed using survival analysis techniques like Kaplan-Meier estimates and Cox regression analysis. Persistence was defined as the duration of continuous therapy after the indicated period of time starting from the index prescription. Prescription gaps longer than 30 days were defined as discontinuation of therapy, but neither switches between alendronate and risedronate or to etidronate, nor switches between daily and weekly intake were considered as a discontinuation. Adherence was measured in terms of the medication possession ratio (MPR), defined as days supplied with medication in percentage of therapy duration. Beneficiaries with a MPR $\geq 0.8$ were considered to be adherent, that is, if they had medication available during $80 \%$ or more of the defined time interval. Recurrent event analysis was performed with the MPR as a time-dependent variable to account for all fractures that could be observed during the observation period. Diagnoses of the following fractures were considered: fracture of femur (including hip; S72); fracture of wrist and hand level (S62); fracture of lumbar vertebra (S32); fracture of thoracic vertebra (S22); fracture of forearm (S52); and fracture of shoulder and upper arm (S42). Diagnoses were included in cases of sick leave as well as hospital stays. It was not possible to distinguish between clinical and non clinical fractures.

\section{Results}

\section{Baseline characteristics and study cohort}

We identified 594,795 (255,509 women, 43.0\%) beneficiaries of the sickness fund who were at least 45 years old and insured for at least 90 days within the 5-year study period. Of these, 4451 patients received an index prescription of alendronate or risedronate (Table 1). A total of 3289 were women (73.9\%), and about half of the patients with an index prescription $(\mathrm{n}=2414 ; 54.2 \%)$ were between 66 and 85 years old.

Of the patients with an index prescription, 3642 (81.8\%) were observed for at least 360 days and 2094 (47.0\%) for at least 720 days after the index prescription date. Most of the patients were those without a previous fracture (Table 2). In total, $31.6 \%$ of the patients with at least 180 days of observation time and $37.7 \%$ of the patients with at least 720 days of observation time had an incident fracture. The proportion of patients with an incident fracture was higher in patients with previous fractures.

\section{Influence of persistence and adherence on fracture risk}

Table 3 shows that in patients with a previous fracture, fracture rates were reduced by $29 \%(p=0.025)$ when comparing 
Table I Distribution of age and gender among patients with an index prescription (patients with observation time of at least 360 days before and 180 days after index prescription, $n=445 \mathrm{I}$ )

\begin{tabular}{|c|c|c|c|c|c|c|}
\hline \multirow[t]{2}{*}{ Age group } & \multicolumn{2}{|l|}{ Men } & \multicolumn{2}{|c|}{ Women } & \multicolumn{2}{|c|}{ Total } \\
\hline & $n$ & $\%$ & $\mathrm{n}$ & $\%$ & $\mathrm{n}$ & $\%$ \\
\hline $45-65$ & 699 & 15.7 & 1227 & 27.6 & 1926 & 43.3 \\
\hline $66-85$ & 451 & 10.1 & 1963 & 44.1 & 2414 & 54.2 \\
\hline$>85$ & 12 & 0.3 & 99 & 2.2 & 111 & 2.5 \\
\hline Total & 1162 & 26.1 & 3289 & 73.9 & 4451 & 100.0 \\
\hline
\end{tabular}

persistent $(n=237)$ and non-persistent patients $(n=110)$ within 180 days (ie, observation time 360 days before and 180 days after index prescription). In the subsample of 298 patients with previous fractures surveyed for 360 days (ie, observation time 360 days before and 360 days after index prescription), persistent use $(\mathrm{n}=141)$ of bisphosphonates was associated with a $45 \%$ lowered risk of fractures $(\mathrm{p}<0.001$ ) compared to non-persistent users. Within 720 days a nonsignificant reduction of $9 \%(p=0.752)$ was observed when comparing persistent $(n=23)$ and non-persistent users $(\mathrm{n}=136)$.

In patients without previous fracture, low incident fracture rates made it difficult to demonstrate a significant effect. However, within 720 days after the index prescription, a nonsignificant reduction of $11 \%(p=0.709)$ in fracture rates was observed in persistent patients $(n=346)$ compared with non-persistent patients $(\mathrm{n}=1589)$.

The effect of adherence on the fracture risk was examined using an extended Cox regression model (Table 4). A good adherence ( $M P R \geq 0.8$ ) reduced the fracture risk by about $39 \%$ in all patients (HR 0.61, 95\% CI 0.47-0.78; $\mathrm{p}<0.01$ ). The fracture risk was significantly increased in patients with a previous fracture (HR 10.32, 95\% CI 8.09-13.16; $\mathrm{p}<0.001$ ) and in beneficiaries elder than 65 years (HR 1.61 95\% CI 1.24-2.07; $\mathrm{p}<0.001$ ). None of the other variables (prior use of glucocorticoids, gender) significantly affected the fracture risk.

The proportion of adherent patients is shown in Table 5. Adherence was higher in patients with a previous fracture. In patients with a previous fracture as well as in patients without previous fracture the proportion of adherent patients declined with observation time.

\section{Discussion}

Osteoporotic fractures are one of the most common causes for chronic disability. ${ }^{4}$ In clinical studies, continuous therapy with oral bisphosphonates was shown to reduce the risk of fractures in osteoporotic patients, but little is known about the influence of suboptimal usage in clinical practice. Therefore, we analyzed the influence of persistence and adherence on fracture risk in 4451 patients with an index prescription of bisphosphonates in a naturalistic setting.

The results showed that persistence with oral bisphosphonates was generally poor. The fracture risk was significantly increased in beneficiaries who had a previous fracture and in beneficiaries elder than 65 years. However, in patients with previous osteoporosis-related fractures, good persistence with and adherence to oral bisphosphonates reduced fracture risk significantly. The effect could be observed within 180 and 360 days after onset of therapy. Reduction of fracture rates in persistent patients was more pronounced in beneficiaries with previous fractures within 360 before the prescription of bisphosphonates.

We measured adherence in terms of the MPR. Two points should be considered while analyzing the effect of

Table 2 Number of patients with and without previous fractures within 360 days before the index prescription in the sub samples with at least 180,360 , and 720 days observation time, respectively

\begin{tabular}{|c|c|c|c|c|c|c|}
\hline \multirow[b]{2}{*}{ Subsample } & \multicolumn{2}{|l|}{ Women } & \multicolumn{2}{|l|}{ Men } & \multicolumn{2}{|l|}{ Total } \\
\hline & $\begin{array}{l}\text { With previous } \\
\text { fracture } n(\%)\end{array}$ & $\begin{array}{l}\text { Without previous } \\
\text { fracture } n(\%)\end{array}$ & $\begin{array}{l}\text { With previous } \\
\text { fracture } n(\%)\end{array}$ & $\begin{array}{l}\text { Without previous } \\
\text { fracture } n(\%)\end{array}$ & $\begin{array}{l}\text { With previous } \\
\text { fracture } n(\%)\end{array}$ & $\begin{array}{l}\text { Without previous } \\
\text { fracture } n(\%)\end{array}$ \\
\hline & \multicolumn{6}{|c|}{ All patients } \\
\hline 180 days, $\mathrm{n}=445 \mathrm{I}$ & $285(6.4)$ & $3004(67.5)$ & $98(2.2)$ & $1064(23.9)$ & $383(8.6)$ & 4068 (91.4) \\
\hline 360 days, $\mathrm{n}=3642$ & $219(6.0)$ & $2456(67.4)$ & $79(2.2)$ & $888(24.4)$ & $298(8.2)$ & $3344(91.8)$ \\
\hline \multirow[t]{2}{*}{720 days, $\mathrm{n}=2094$} & $117(5.6)$ & $1388(66.3)$ & $42(2.0)$ & $547(26.1)$ & $159(7.6)$ & $1935(92.4)$ \\
\hline & \multicolumn{6}{|c|}{ Patients with incident fracture } \\
\hline 180 days, $\mathrm{n}=445 \mathrm{I}$ & $87(30.5)$ & $0(0.0)$ & $34(34.7)$ & $0(0.0)$ & $|2|(3 \mid .6)$ & $0(0.0)$ \\
\hline 360 days, $\mathrm{n}=3642$ & $78(35.6)$ & $4 \mathrm{I}(\mathrm{I} .7)$ & $31(39.2)$ & $10(1.1)$ & $109(36.6)$ & $51(1.5)$ \\
\hline 720 days, $\mathrm{n}=2094$ & $39(33.3)$ & $52(3.7)$ & $21(50.0)$ & $16(37.7)$ & $60(37.7)$ & $68(3.5)$ \\
\hline
\end{tabular}


Table 3 Beneficiaries with previous fractures before the index prescription: fracture rates within I80 days $(n=383), 360$ days $(n=298)$ and $720(n=159)$, respectively according to persistence

\begin{tabular}{|c|c|c|c|c|c|c|}
\hline & \multicolumn{2}{|c|}{ Without previous fracture } & \multicolumn{2}{|c|}{ With previous fracture } & \multirow{2}{*}{$\begin{array}{l}\text { Reduction } \\
\%\end{array}$} & \multirow[t]{2}{*}{ p-value } \\
\hline & $\mathbf{n}$ & $\%$ & $\mathbf{n}$ & $\%$ & & \\
\hline \multicolumn{7}{|c|}{ Subsample $\mathrm{I} 80$ days, $\mathrm{n}=383$} \\
\hline Non-persistent, $\mathrm{n}=\mathrm{I} 10$ & 66 & 60.0 & 44 & 40.0 & \multirow{2}{*}{29.5} & \multirow{2}{*}{0.025} \\
\hline Persistent, $\mathrm{n}=273$ & 196 & 71.8 & 77 & 28.2 & & \\
\hline \multicolumn{7}{|c|}{ Subsample 360 days, $n=298$} \\
\hline Non-persistent, $\mathrm{n}=157$ & 84 & 53.5 & 73 & 46.5 & \multirow{2}{*}{45.1} & \multirow{2}{*}{$<0.001$} \\
\hline Persistent, $\mathrm{n}=|4|$ & 105 & 74.5 & 36 & 25.5 & & \\
\hline \multicolumn{7}{|c|}{ Subsample 720 days, $\mathrm{n}=159$} \\
\hline Non-persistent, $\mathrm{n}=136$ & 84 & 61.8 & 52 & 38.2 & \multirow{2}{*}{9.0} & \multirow{2}{*}{0.752} \\
\hline Persistent, $\mathrm{n}=23$ & 15 & 65.2 & 8 & 34.8 & & \\
\hline
\end{tabular}

adherence: (i) adherence changes over time in individual patients, ${ }^{5}$ (ii) patients often experience more than one fracture during the observation period, thus it would be more correct to account for all fractures that could be observed. Therefore, a recurrent event analysis was performed with MPR as a time-dependent variable.

The underlying claims database contains data collected routinely from the ambulatory and the inpatient setting with all prescriptions and all hospital stays recorded. The data have been recorded for billing purposes and have not been influenced by a study or any selection bias. Compared with randomized controlled trials (RCTs), studies based on claims data reflect a real-life setting.

We performed a retrospective cohort study, which may have several limitations. Our analyses may be limited by some factors related to our database: the underlying database is not representative of the general population. Beneficiaries of the sickness fund are younger than the general population (72.2\% aged between 45 and 54 years) and men are slightly over-represented (57.0\%). Data on important risks of osteoporosis are not available in our database, especially information on weight, bone mineral density, or healthrelated behavior such as smoking and physical activity. There also may be some limitation due to data recovery, although we think that the possible bias is low: The routine data do cover all prescriptions which are dispensed in a pharmacy as well as all hospital stays of the patients. Therefore, no clinical fracture should have been missed. Because we have included all diagnoses of hospital stays and sick leave cases (main diagnosis as well as additional diagnoses), we cannot eliminate the possibility that some fractures were only radiographic and not clinical.

Table 4 Extended Cox regression model of incident fractures

\begin{tabular}{|c|c|c|c|c|c|}
\hline \multicolumn{2}{|l|}{ Parameter } & \multirow{2}{*}{$\begin{array}{l}\text { Hazard ratio } \\
1.00\end{array}$} & \multirow[t]{2}{*}{ p-value } & \multicolumn{2}{|c|}{$95 \% \mathrm{Cl}$} \\
\hline MPR & $<0.8$ (non-adherent) & & & & \\
\hline & $\geq 0.8$ (adherent) & 0.61 & 0.00 & 0.47 & 0.78 \\
\hline \multirow[t]{3}{*}{ Age group } & $<65$ & 0.00 & & & \\
\hline & $66-85$ & 1.61 & 0.00 & 1.24 & 2.07 \\
\hline & $>85$ & 1.74 & 0.05 & 1.01 & 0.03 \\
\hline Fracture before & No & 1.00 & & & \\
\hline index date & yes & 10.32 & 0.00 & 8.09 & 13.16 \\
\hline \multirow[t]{2}{*}{ Gender } & Men & 1.00 & & & \\
\hline & Women & 1.00 & 0.99 & 0.77 & 1.30 \\
\hline \multirow{2}{*}{$\begin{array}{l}\text { Prescription of } \\
\text { glucocorticoids }\end{array}$} & No & 1.00 & & & \\
\hline & Yes & 1.23 & 0.17 & 0.91 & 1.65 \\
\hline
\end{tabular}


Table 5 Adherence in patients with $(n=383)$ and without previous fracture $(n=4068)$

\begin{tabular}{|c|c|c|c|c|c|c|}
\hline \multirow[t]{3}{*}{$\begin{array}{l}\text { Observation time after } \\
\text { index prescription }\end{array}$} & \multicolumn{3}{|c|}{$\begin{array}{l}\text { Without previous } \\
\text { fracture }\end{array}$} & \multicolumn{3}{|c|}{$\begin{array}{l}\text { With previous } \\
\text { fracture }\end{array}$} \\
\hline & \multirow{2}{*}{$\begin{array}{l}\text { All } \\
\mathrm{n}\end{array}$} & \multicolumn{2}{|c|}{ Adherent patients } & \multirow{2}{*}{ All } & \multicolumn{2}{|c|}{ Adherent patients } \\
\hline & & $\mathbf{n}$ & $\%$ & & $n$ & $\%$ \\
\hline Adherent within 180 days & 4068 & 2,261 & 55.6 & 383 & 236 & 61.6 \\
\hline Adherent within 360 days & 3344 & $\mathrm{I}, 444$ & 43.2 & 298 & 147 & 49.3 \\
\hline Adherent within 720 days & 1935 & 574 & 29.7 & 159 & 67 & 42.1 \\
\hline
\end{tabular}

For the following reasons, we did not differentiate between the drugs used: i) We only considered drugs approved for the therapy of osteoporosis. Patients with other diseases enhancing the fracture risk (cancer, Morbus Paget, AIDS) were excluded. ii) The proportion of etidronate in the German market is marginal. ii) The current German guideline for the diagnosis and therapy of osteoporosis does not indicate any difference between alendronate and risedronate considering the reduction of fracture risk..$^{10}$ Therefore, we assume that we included only patients with a bisphosphonate therapy for the prevention of osteoporosis related fractures.

Due to the relatively low rate of fractures in patients without known fractures at study entry, in further studies a longer follow-up of patients with continuous oral bisphosphonate therapy may be necessary to show a significant fracture reduction by therapy in this subgroup.

Until now, only a few studies evaluated the relationship between compliance and persistence with bisphosphonates on fracture risk in clinical practice, predominantly in postmenopausal women. Despite methodological differences, our results are consistent with findings of other studies that report decreased fracture risks in compliant patients. ${ }^{3-5}$ In a study among 35,537 women with a minimum age of 45 years, a $21 \%$ reduction in fracture risk in compliant women was observed compared to non-compliant patients ( $\mathrm{p}<0.001)$. Similarly, further studies presented in a review by Seeman et $\mathrm{al}^{7}$ showed that the probability of sustaining a fracture is higher in poor compliers. Our results are also in line with the results of a nested case-control study reporting that positive effects of bisphosphonate therapy can be observed within 180 days after onset of therapy. ${ }^{8}$ Our observations are similar to those reported in a retrospective study investigating the impact of compliance and adherence on fracture risk. In the study published by Rabenda et $\mathrm{al}^{9}$ the MPR was a significant predictor of incident fractures, the relative risk reduction for hip fracture was $60 \%$ in persistent versus non-persistent patients $(\mathrm{p}<0.0001)$.

There have been already similar studies on the prevention of osteoporosis related fractures $\left(\mathrm{eg},{ }^{11}\right)$, which have shown the effectiveness of bisphosphonate therapy on fracture risk reduction. Our analysis shows, that the effectiveness is not only true for the setting of an RCT, but also the real-life setting. Moreover, our analysis focused on the influence of persistence and adherence to bisphosphonate therapy on fracture risk.

In conclusion, our results confirm that in actual practice improving adherence and persistence with bisphosphonates may reduce the risk of osteoporotic fractures in patients with fracture history.

\section{Disclosures}

This work was supported by Novartis Pharma AG. A Höer, C Seidlitz, H Gothe, and G Schiffhorst are employees (and B Häussler is the Director) of IGES institute, an independent research organization that received funding from Novartis Pharma AG for this study. M Olson is employee of Novartis Pharma AG. Novartis Pharma GmbH manufactures bisphosphonates. P Hadji is the Head of the Department of Endocrinology Reproductive Medicine and Osteoporosis, University Hospital of Giessen and Marburg GmbH.

\section{References}

1. List of National and Regional Osteoporosis Guidelines. International Osteoporosis Foundation. Available from: http://www.iofbonehealth. org/health-professionals/national-regional-guidelines/evidence-basedguidelines.html (Accessed December 04, 2007).

2. Hodsman AB, Hanley DA, Josse R. Do bisphosphonates reduce the risk of osteoporotic fractures? An evaluation of the evidence to date. CMAJ. 2002;166:1426-1430.

3. McCombs JS, Thiebaud P, McLaughlin-Miley C, et al. Compliance with drug therapies for the treatment and prevention of osteoporosis. Maturitas. 2004;48:271-287.

4. Penning-van Beest FJA, Erkens JA, Olson M, et al. Loss of treatment benefit due to low compliance with bisphosphonate therapy. Osteoporos Int. 2008;19:511-517.

5. Caro JJ, Ishak KJ, Huybrechts KF, et al. The impact of compliance with osteoporosis therapy on fracture rates in actual practice. Osteoporos Int. 2004;15:1003-1008.

6. Siris ES, Harris ST, Rosen CJ, et al. Adherence to bisphosphonate therapy and fracture rates in osteoporotic women: relationship to vertebral and nonvertebral fractures from 2 US claims databases. Mayo Clin Proc. 2006;81:1013-1022. 
7. Seeman E, Compston J, Adachi J, et al. Non-compliance: the Achilles' heel of anti-fracture efficacy. Osteoporos Int. 2007;18:711-719.

8. Weycker D, Macarios D, Edelsberg J, et al. Compliance with drug therapy for postmenopausal osteoporosis. Osteoporos Int. 2006;17:1645-1652.

9. Rabenda V, Mertens R, Fabri V, et al. Adherence to bisphosphonates therapy and hip fracture risk in osteoporotic women. Osteoporos Int. 2008;19(6):811-818.
10. DVO (Dachverband der Deutschsprachigen Wissenschaftlichen Osteologischen Gesellschaften). Prophylaxe, Diagnostik und Therapie der Osteoporose. 2006

11. Stevenson M, Jones ML, De Nigris E, Brewer N, Davis S, Oakley J. A systematic review and economic evaluation of alendronate, etidronate, risedronate, raloxifene and teriparatide for the prevention and treatment of postmenopausal osteoporosis. Health Technol Assess. 2005;9(22):1-160. 